\title{
Comparison of Treatment Response before and after Antiobsessive Therapy among Psychiatric Patients with Obsessive Compulsive Disorder
}

\author{
Belbase $\mathrm{M}^{1}$, Adhikari J²
}

\begin{abstract}
Introduction: Obsessive compulsive disorder is a common, chronic and disabling disorder marked by obsessions and/or compulsions. This study tries to find the demographic profiles, severity and response of antiobsessive drugs in young and adult patients with obsessive compulsive disorder. Aims: To study the socio-demographic profile, severity and treatment response to commonly used antiobsessive medications in male and female, and young and adults. Methods: This is a hospital based experimental study done in patients attending to psychiatry out-patient department over one year from February 2020 to January 2021.2 Diagnosis of obsessive compulsive disorder was made based on International Classification of Disease- 10 criteria for research. Yale-Brown obsessive compulsive scale check list (adult and children) was applied in those patients and recorded accordingly on baseline (week 0) and patients were treated with specific serotonin reuptake inhibitors or tricyclic antidepressants in therapeutic doses for 6 weeks. On follow up at week 6 , they were again reassessed and the scores were recorded and analyzed. Results: Among the total study subject (N-52), 26(50\%) were male and 26(50\%) were females. Patients in age bracket 20-29 is the most common age group representing $18(34.6 \%)$. Mean age of patients is $30.36 \pm 11.93$ years $(28.65 \pm 9.80$ in male and $32.04 \pm 13.73$ in female). Severe form of obsessive compulsive disorder was the most common type that represent 33(63.5\%) followed by moderate 16(30.8\%) and extreme $3(5.7 \%)$. There is a difference of treatment response of antiobsessive therapy in male and female with statistical significance $(p=0.039)$. Conclusion: This study shows that obsessive compulsive disorder is most commonly found in $20-29$ age group and the severe type is the most common. There is a significant difference in treatment response of antiobsessive therapy in male and female.
\end{abstract}

Keywords: Antiobsessive therapy, Obsessive compulsive disorders, Treatment response

Authors:

1. Dr. Mohan Belbase

2. Dr. Jyoti Adhikari

${ }^{1}$ Department of Psychiatry, Nepalgunj Medical College and Teaching Hospital, Kohalpur, Banke

${ }^{2}$ Department of Pediatrics, Nepalgunj Medical College and Teaching Hospital, Kohalpur, Banke

\author{
Address for Correspondence: \\ Dr. Mohan Belbase \\ Associate Professor and Head \\ Department of Psychiatry \\ Nepalgunj Medical College and Teaching Hospital \\ Kohalpur, Banke \\ Email: mohanbelbase90@gmail.com
}

\section{INTRODUCTION}

Obsessive compulsive disorder (OCD) is a common, chronic and disabling disorder marked by obsessions and/or compulsions that are ego dystonic and cause significant distress to the patients and their families. ${ }^{1}$ Once considered rare, it is now known to be quite prevalent with life time prevalence of 2.3 percent. Some patients only have obsessions while others may only have compulsions but majority will have both. ${ }^{2}$ OCD is comorbid with depression, phobia, panic disorders, alcohol use disorders, other substance related disorders and schizophrenia. ${ }^{3}$ OCD has median age of onset of 19 years and though community studies shows higher prevalence in females but in clinical contest, there ratio is almost equal. ${ }^{2}$ Several studies have found that most common obsession is contamination while most common compulsion is checking. ${ }^{4}$ People with OCD are generally misjudged as having bad habits and thus face criticism, discrimination and sometime even inhuman punishments. ${ }^{5}$ Studies from developing world shows sociocultural differences in phenomenology, comorbodities and treatment response patterns and it is unclear how these differences manifest in term of age and gender. ${ }^{6}$ The severity of OCD can befound by using Yale-Brown Obsessive Compulsive Scale (Y-BOCS) which has established reliability and validity. ${ }^{7}$ Commonly used medicine in OCD are SSRI (specific serotonin reuptake inhibitors) and TCA (tricyclic antidepressants). They are equally effective but with differences in their side effects. Behavioral therapies combined pharmacotherapy is the best treatment choice. ${ }^{5}$ This article tries to see the response of antiobsessive drugs in OCD patients of different age and gender.

\section{METHODS}

This is a hospital based experimental study done in patients 
attending to psychiatry outpatient department in Nepalgunj Medical College, Kohalpur. Diagnosis of OCD was made based on ICD-10 criteria for research. ${ }^{8}$ Diagnosis was made by consultant psychiatrist and all the demographic variables were recorded in the clinical porforma developed by the department of psychiatry. Y-BOCS check list (adult and children) was applied in those patients and recorded accordingly on baseline (week 0) and patients were treated with SSRI or TCA in therapeutic doses for 6 weeks. On follow up at 6 weeks, they were again reassessed using Y-BOCS and the scores were recorded. Patients of either gender who gave written consent were included in the study. Patients who did not give consent, who were dependent on any psychoactive substance, had head injury, delirium, serious medical problems, dementia, psychosis and obsessive compulsive personality were excluded from the study. Total 52 patients were included from February 2020 to January 2021 in one year. Y-BOCS was used to record the severity and symptoms of OCD on week zero (0) first and week six (6) after the pharmacotherapy of either SSRI or TCA in therapeutic dose. Y-BOCS is a clinician administered semistructured interview that includes symptom checklist with a 10 item severity rating scale. Children Y-BOCS version was used to record the OCD in children and adolescents. The data were assessed using SPSS 20 and comparison of treatment response in children versus adults and male versus female was done.

\section{Instruments used}

1. The ICD 10 classification of mental and behavioral disorders, diagnostic criteria for research.

\section{Semi-structured porforma.}

3. Y-BOCS check list (Adult and Children's Yale Brown Obsessive Compulsive Scale). It is a 10 item clinician administered checklist which was generated on the basis of clinical interviews with OCD patients in the 1980s (Goodman et al, 1989a; Storch et al, 2007; Goodman, 2013).

\section{RESULTS}

Among the total study subjects (N-52), 26 (50\%) were male and 26 (50 \%) were female. Patients in age bracket $20-29$ was the most common group representing $18(34.6 \%)$ while it was least for less than 10 years. Most patients were literate (about $76.9 \%)$ while $15.4 \%$ had higher education. Students and housewives were most affected and mostly they were from lower socioeconomic background.

Mean age of patients in our study was $30.36 \pm 11.93$ years (28.65 \pm 9.80 in male and $32.04 \pm 13.73$ in female). Severe form of OCD was the most common type of OCD that represent $33(63.5 \%)$ followed by moderate $16(30.8 \%)$ and extreme $3(5.7 \%)$. The comparison of Y-BOCS scores on base line and after 6 weeks of antiobsessive treatment in all the patients using paired t-test was very significant $(p<0.001)$. After 6 weeks of treatment, Y-BOCS scores decreased with mean of $7.115 \pm 2.698$ and $95 \%$ confidence of decreasing mean is 6.3647.867 which indicates data being highly reliable. There was a difference of treatment response of antiobsessive therapy in male and female which is significant $(p=0.039)$. When the treatment response in younger (less than 20 years) and older
(20 years or more) was compared, the difference was not significant.

\begin{tabular}{|c|c|c|c|}
\hline Characteristics & Categories & $\begin{array}{l}\text { Frequency } \\
(\mathrm{N}=52)\end{array}$ & Percentage \\
\hline \multirow{7}{*}{ Age } & $<10$ & 2 & 3.9 \\
\hline & $10-19$ & 6 & 11.5 \\
\hline & $20-29$ & 18 & 34.6 \\
\hline & & & \\
\hline & $30-39$ & 14 & 26.9 \\
\hline & $40-49$ & 10 & 19.2 \\
\hline & $>50$ & 2 & 3.9 \\
\hline \multirow{2}{*}{ Gender } & Male & 26 & 50 \\
\hline & Female & 26 & 50 \\
\hline \multirow{3}{*}{ Marital status } & Married & 32 & 61.5 \\
\hline & & & \\
\hline & Unmarried & 20 & 38.5 \\
\hline \multirow{3}{*}{ Religion } & Hindu & 48 & 92.4 \\
\hline & Muslim & 2 & 3.8 \\
\hline & Christian & 2 & 3.8 \\
\hline \multirow{3}{*}{ Education } & Illiterate & 4 & 7.7 \\
\hline & & & \\
\hline & Literate & 48 & 92.3 \\
\hline \multirow{5}{*}{ Occupation } & Student & 22 & 42.3 \\
\hline & Housewife & 16 & 30.8 \\
\hline & & & \\
\hline & Jobholder & 6 & 11.5 \\
\hline & Unemployed & 8 & 15.4 \\
\hline \multirow{2}{*}{$\begin{array}{l}\text { Socioeconomic } \\
\text { status }\end{array}$} & Lower & 40 & 76.9 \\
\hline & Lower-middle & 12 & 23.1 \\
\hline
\end{tabular}

Table I: Demographic profile of the OCD patients

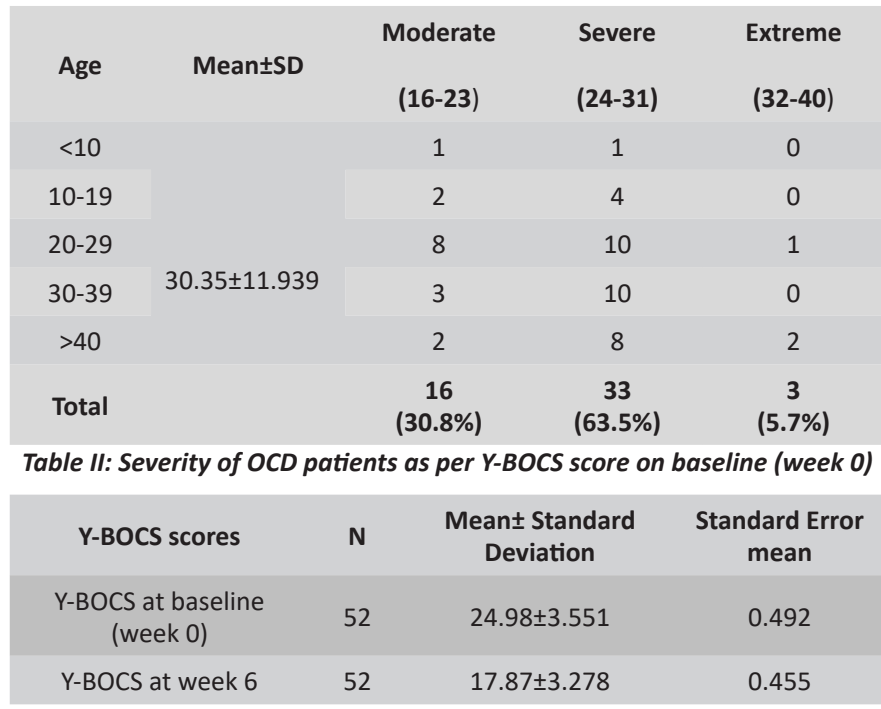

Table III: Y-BOCS scores on week 0 and week 6 with their mean and 


\section{standard deviation}

\begin{tabular}{|c|c|c|c|c|c|c|c|}
\hline \multirow[t]{2}{*}{$\begin{array}{c}\text { Paired } \\
\text { Differences }\end{array}$} & \multirow[t]{2}{*}{ Mean \pm SD } & \multirow{2}{*}{$\begin{array}{c}\text { Standard } \\
\text { Error } \\
\text { Mean }\end{array}$} & \multicolumn{2}{|c|}{$\begin{array}{l}95 \% \text { confidence } \\
\text { interval of } \\
\text { difference }\end{array}$} & \multirow[t]{2}{*}{$t$} & \multirow[t]{2}{*}{ df } & \multirow[t]{2}{*}{$\begin{array}{l}\text { Significance } \\
\text { (two tailed) }\end{array}$} \\
\hline & & & Lower & Upper & & & \\
\hline $\begin{array}{l}\text { Y-BOCS at } \\
\text { baseline } \\
\text { (week 0) - } \\
\text { Y-BOCS at } \\
\text { week } 6\end{array}$ & $7.115 \pm 2.698$ & 0.374 & 6.364 & 7.867 & 19.016 & 51 & $<0.001$ \\
\hline
\end{tabular}

Table IV: Paired 2-tailed t-test to show the difference in Y-BOCS scores after antiobsessive treatment

\begin{tabular}{|lcccc|}
\hline \multicolumn{1}{|c}{ Variables } & Gender & N & Mean \pm SD & $\begin{array}{c}\text { t-test for equality of } \\
\text { means with } \\
\text { Significance (two- } \\
\text { tailed) }\end{array}$ \\
\hline $\begin{array}{l}\text { Y-BOCS at } \\
\text { baseline (week 0) }\end{array}$ & Male & 26 & $24.73 \pm 4.285$ & \\
\hline Y-BOCS at week 6 & Male & 26 & $16.85 \pm 3.652$ & 0.023 \\
\hline $\begin{array}{l}\text { Difference } \\
\text { Y-BOCS at }\end{array}$ & Female & 26 & $18.88 \pm 2.535$ & \\
$\begin{array}{l}\text { baseline(week } \\
\text { 0)-Y-BOCS at } \\
\text { week 6 }\end{array}$ & Male & 26 & $7.88 \pm 2.944$ & \\
\hline
\end{tabular}

Table V: Group statistics and independent samples test with Y-BOCS score on week 0 and week 6 in male and female with paired 2-tailed t-test to compare the gender differences of antiobsessive drugs response

\begin{tabular}{lcccc} 
& Age in years & N & Mean \pm SD & $\begin{array}{l}\text { Significance } \\
\text { (two tailed) }\end{array}$ \\
$\begin{array}{l}\text { Y-BOSC at } \\
\text { baseline (week } \\
\text { 0) }\end{array}$ & $<20$ & 8 & $24.40 \pm 3.162$ & \\
$\begin{array}{l}\text { Y-BOSC at } \\
\text { week 6 }\end{array}$ & $\geq 20$ & 44 & $25.07 \pm 3.643$ & \\
$\begin{array}{l}\text { Difference } \\
\text { Y-BOCS at }\end{array}$ & $<20$ & 8 & $18.13 \pm 1.727$ & \\
$\begin{array}{l}\text { baseline(week } \\
\text { 0) - Y-BOCS at } \\
\text { week 6 }\end{array}$ & $\geq 20$ & 44 & $17.82 \pm 3.499$ & \\
\hline
\end{tabular}

Table VI: Showing differences of response of antiobsessive treatment in young patients ( $<20$ years) versus older ( $\geq 20$ years) by using 2 -tailed group t-test

\section{DISCUSSION}

In our study male and female ratio of patient for OCD is equal which is consistent with other similar previous studies and most of text books as OCD in adults is equal in male and female. ${ }^{1,2,3}$ Age 20-29 is the most common age group in our study that represents about $34.6 \%$. It is similar to one study done in Dharan, Neapl in 45 OCD patients in which the most common age group was $20-29$ years comprising 39
$\%$ of total study population. ${ }^{9}$ It is also consistent with most of the textbooks as mean onset of OCD is 19 years. Only in one-quarter of cases, the onset is by age 10 and female have onset more during adolescence, pregnancy and puerperium. Onset after 30 years is rare. ${ }^{2}$ Most of patients in our study are married $(61.5 \%)$ which is not consistent with the findings from western literatures which mention that most patients are unmarried, divorced or separated. ${ }^{7}$ This may be due to our culture of early marriage, less frequent divorces and even a belief that mental illness gets cured by getting married. As per the Y-BOCS scoring checklist applied in our study, severe form of OCD is in $33(63.5 \%)$ while moderate OCD in $16(30.8$ $\%)$. It is consistent with the finding of the study from eastern Nepal where two third of the study subject were having severe OCD as per the Y-BOCS scoring. ${ }^{9}$ We could not get subclinical and mild form of OCD in our study that may be because of the sampling done from a tertiary care centre where most of the patients visit when they are severely ill or referred after several therapeutic trails in periphery through different medical and non-medical pathways. Regarding comparison of $Y$-BOCS scores on week 0 (before treatment) and week 6 (after antiobsessive treatment), the difference is highly significant with $\mathrm{P}$ value of $0.001(<0.05)$. This indicates the treatment brings significant changes in Y-BOCS scores or response of antiobsessive therapy which is shown by other number of clinical trials and meta-analysis. ${ }^{1,2,3}$ Regarding the difference of response with antiobsessive drugs in male and female, it is significant with $p$ value of $0.039(<0.05)$. It is comparable with a study conducted in 2 multicentre, double blind trail with 519 adults with OCD in which male gender and OCD with longer duration of illness were less likely to respond to clomipramine though the difference was not statistically significant. ${ }^{10}$ Howeverit is not consistent with another similar study done in OCD patients which did not show gender difference in treatment outcome though gender may have played role in onset, presentation and impact. ${ }^{11}$ Our finding may be due to more female presenting with comorbid depression and anxiety disorder along with OCD and they may have better treatment response as antiobsessive drugs are antidepressants and anxiolytics as well. Furthermore, more male have comorbid tic disorder, substance related issues including alcohol to complicate the matter. In the study done in Dharan, it was found that depression and anxiety disorders were the most common psychiatry comorbidities in Nepalese OCD patients. ${ }^{9}$

Another comparative study done to see the effects of gender on clinical feature and therapeutic response in OCD in 69 patients ( 32 male and 37 female), male patients had earlier age of onset and greater global severity while female had more severe depressive symptoms. No significant difference was observed between male and female with regards to therapeutic response. ${ }^{12}$

Regarding the difference in young (less than 20 years) and older (20 years and more) patients on antiobsessive drugs, there is no significant difference. This in consistent with a similar study done by Leonard et al.(1989) in a 10 week double blind crossover study of clomipramine and desipramine in which, though clomipramine was superior to desipramine in 
reducing obsessive compulsive symptoms but age of onset, duration of symptoms, symptom severity did not predict the clinical outcome. ${ }^{7}$

\section{LIMITATIONS}

Small sample size, single follow up, non blind type of study without placebo controls are some of limitations of this study.

\section{CONCLUSION}

This study shows the prevalance of OCD from young age to late adulthood with most commonly in 20-29 age group. Severe type of OCD is the most common type of OCD. Treatment with antiobsessive drugs brings about significant changes in symptom profile of OCD patients. There is a difference of treatment response of antiobsessive therapy in male and female which is significant with $p$ value of $0.039(<0.05)$.

\section{ACKNOWLEDGEMENT}

My sincere thanks to LBEA, NGMCTH Kohalpur and Principal NGMC for giving me this opportunity. Thanks to my department collegues and my students Dr. Rakesh and Dr. Saroj.

\section{REFERENCES}

1. Zohar J, Fostick L, Juven-Wetzler E. Obsessive-compulsive disorder. In: Gelder MG, Andreasen NC, Lopez-lbor JJ, Geddfes JR, editors. New oxford textbook of psychiatry. $2^{\text {nd }}$ ed. New York: Oxford University Press; 2009. p. 765-70.

2. Stein DJ, Lochner C. Obsessive compulsive and related disorders. In: Sadock BJ, Sadock VA, Ruiz P, editors. Comprehensive textbook of psychiatry. $10^{\text {th }}$ ed. Philadelphia: Wolters Kluwer; 2017. p. 1785-98.

3. Khanna S. Obsessive compulsive disorder. In: Vyas JN, Auja $\mathrm{N}$, editors. Textbook of postgraduate psychiatry. $2^{\text {nd }} \mathrm{ed}$. New Delhi: Jaypee Brothers Medical Publisers; 1999. p. 263-74.

4. Pato MT, Steketee G, Eisen JL, Yip AG, Philips KA. Obsessive compulsive and related disorders. In: Tasman A, Kay J, Lieberman JA, First MB, Riba MB, editors. Psychiatry. $4^{\text {th }}$ ed. The Atrium: Wiley Blackwell; 2015. p. 1095-1123.

5. Shakya R. Advocating psychiatry in Nepal. 2013. p. 32.

6. Reddy YC, Rao NP, Khanna S. An overview of Indian research in obsessive compulsive disorder. Indian J Psychiatry.2010;52:S200-9. [PMC free article][pubMed] [Google Scholar]

7. Eisen JL, Yip AG, Mancebo MC, Pinto A, Rasmussen SA. Phenomenology of obsessive-compulsive disorder. In: Stein DJ, Hollender E, Rothbaum BO, editors. Textbook of Anxiety Disorder. $2^{\text {nd }}$ ed. Banglore: Panther Publishers Private Limited;2010. p. 261-352.

8. World Health Organization. The ICD-10 Classification of Mental and Behavioral Disorders Diagnostic Criteria for Research. Geneva: WHO; 1993. with Obsessive Compulsive Disorder. Journal of psychiatrst's Association of Nepal.2020;9(1);34-39.

10. DeVeaugh-Geiss J, Kartz R, Landau P, Goodman W, Rasmusen S. Clinical predictors of treatment response in obsessive compulsive disorder: exploratory analyses from multicentre trails of clomipramine. Psychopharmacol Bull. 1990;26(1):54-9. PMID: 2196627.

11. Mathes BM, Morabito DM, Schmidt NB. Epidemiological and Clinical Gender Differences in OCD. Curr Psychiatry Rep. [Internet]. 2019 Apr23 [ cited 2021, Apr 20];21(5):36. doi: 10.1007/s11920-019-1015-2. PMID: 31016410.

12. Leonardo F, Carla M, Marcio V. The effect of gender on the clinical features and therapeutic response in obsessive compulsive disorder. Brazilian Journal of Psychiatry. [Internet].2002 Mar [Cited 2021, Mar 18]; 24(1); https://doi. org/10.1590/s1516-44462002000100005.

9. Shakya DR. Comorbidities in Nepalese psychiatry outpatients 